\title{
BMJ Open Is age more than manual material handling associated with lumbar vertebral body and disc changes? A cross-sectional multicentre MRI study
}

\author{
Francesco S Violante, ${ }^{1}$ Maurizio Zompatori, ${ }^{2}$ Piero Lovreglio, ${ }^{3}$ Pietro Apostoli, ${ }^{4}$ \\ Francesco Marinelli, ${ }^{1}$ Roberta Bonfiglioli ${ }^{1}$
}

To cite: Violante FS, Zompatori M, Lovreglio $\mathrm{P}$, et al. Is age more than manual material handling associated with lumbar vertebral body and disc changes? A cross-sectional multicentre MRI study. BMJ Open 2019;9:e029657. doi:10.1136/ bmjopen-2019-029657

- Prepublication history for this paper is available online. To view these files, please visit the journal online (http://dx.doi org/10.1136/bmjopen-2019029657).

Received 04 February 2019 Revised 07 August 2019 Accepted 23 August 2019

Check for updates

(c) Author(s) (or their employer(s)) 2019. Re-use permitted under CC BY-NC. No commercial re-use. See rights and permissions. Published by BMJ.

${ }^{1}$ Department of Medical and Surgical Sciences, University of Bologna, Bologna, Italy ${ }^{2}$ Department of Radiology, Ospedale San Giuseppe MultiMedica, Milan, Milan, Italy ${ }^{3}$ Interdisciplinary Department of Medicine, University of Bari Aldo Moro, Bari, Italy

${ }^{4}$ Department of Medical and Surgical Sciences, Radiological Sciences and Public Health, University of Brescia, Brescia, Italy

Correspondence to Dr Francesco S Violante; francesco.violante@unibo.it

\section{ABSTRACT}

Objective Conflicting evidence exists to what extent manual material handling (MMH) causes lumbar disc disease, lack of evidence exist that this effect takes place especially at L5-S1 level, where the greatest moment occurs. The aim was to assess if lumbar vertebral body and disc changes are more common in people whose job involves significant MMH and, if so, to evaluate if lumbar vertebral body and disc changes are more prevalent in the lower part of the lumbar spine (L4-L5 and L5-S1).

Design Observational, cross-sectional, with quasi-random recruitment.

Setting Outpatient radiology units of three large hospitals in northern (Bologna and Brescia) and southern (Bari) Italy. Participants 183 consecutive adult subjects (89 males, 94 females) aged 20-70 years referred by the general practitioner or a specialist for MRI of the lumbar spine.

\section{Primary and secondary outcome}

measures Neuroradiologists (blind to clinical assessment) evaluated the prevalence of intervertebral disc and vertebral body changes in standardised MRI examinations. History of personal and family musculoskeletal diseases and injuries, current and previous MMH at work and during leisure time were assessed by interview and selfadministered questionnaire.

Results Participants were classified according their occupational exposure to MMH. No association was found between MMH and vertebral body and intervertebral disc changes, whereas age over 45 years was consistently associated with more disc extension beyond the interspace changes, Pfirrmann changes, osteophytes and Modic changes: the association was statistically significant at the conventional $5 \%$ level.

Conclusions Age, and not MMH, seems to primarily affect the presence of intervertebral disc changes; prospective studies are needed to better explore the relationship between MMH and the possible presence (and level) of lumbar vertebral body and/or disc changes.

\section{INTRODUCTION}

Low back pain (LBP) is a significant societal and medical problem. LBP is highly prevalent in all populations and disability-adjusted life years associated with this condition have constantly increased worldwide. People with
Strengths and limitations of this study

Multicentre MRI study of 183 consecutive adult subjects referred for imaging of the lumbar spine.

- Detailed information about lumbar intervertebral disc structure and morphology, vertebral endplate and bone marrow changes, associated with personal and occupational factors, are provided.

- Consensus criteria to enhance accuracy and repeatability of imaging reporting were agreed on; however, radiologists independently read MRI within each participating centre.

- Limitations of the study are the cross-sectional design and the self-reported questionnaire-based exposure assessment.

physically demanding jobs are at greatest risk of reporting LBP. ${ }^{1}$ Epidemiological literature suggests a causal link between excessive occupational manual material handling $(\mathrm{MMH})$ and increased risk of LBP (mostly of the recurrent type) in some occupational groups ${ }^{2}$ : there are, however, critics to this view. The results of a systematic review did not support a causal association between workplace manual handling or assisting patients and LBP in a Bradford-Hill framework. ${ }^{3}$

Whereas the causal association between MMH and LBP (at least, the postexertional variety) is broadly accepted, there is less information on MMH as a possible cause of lumbar vertebrae or discs changes ${ }^{45}$ and especially about the specific level of vertebral or disc change due to MMH, if any. ${ }^{6}$ Moreover, genetics seems to be increasingly recognised as a strong causative factor for disc disease, ${ }^{78}$ explaining most of the disc degeneration found in twin studies. ${ }^{9}$

Whether MMH is a possible cause of disc diseases is a relevant issue: given the large prevalence of this condition in the population, ${ }^{1}$ one should expect that preventive effort towards 
MMH could lower not only the incidence (and, later, the prevalence) of LBP but also of disc disease and their related huge health cost. As there are five lumbar vertebrae and discs, if MMH is a cause of vertebral and disc changes it is relevant too (both for preventive purposes and medicolegal implications), to understand if there is a specific segment of the lumbar spine which is affected by MMH. Apparently, epidemiologists have so far investigated the hypothesis that MMH may cause disc disease at any level in the lumbar spine (from L1-L2 to L5-S1). ${ }^{410-13}$ However, this hypothesis is not consistent with current biomechanical knowledge, which has demonstrated that during $\mathrm{MMH}$ the disc which incurs in the greatest load (in terms of vertical and shear forces) is L5-S1. ${ }^{14}$

Based on this background knowledge, we designed this study to explore the following 'a priori' hypotheses:

1. If $\mathrm{MMH}$ is a definite cause of (or significantly contribute to) lumbar vertebral body and disc changes, the latter should be more common in people who perform $\mathrm{MMH}$, compared with a control group.

2. If more common in people who perform MMH, lumbar vertebral body and disc changes should be more prevalent where MMH produces the greatest load on lumbar spine (L5 body and L5-S1 disc).

\section{METHODS}

\section{Clinical and imaging studies}

We invited to participate all the patients who were referred for MRI of the lumbar spine to the outpatient radiology units of three large hospitals in northern (Bologna and Brescia) and southern (Bari) Italy. Participants were consecutively recruited during the period October 2013 to March 2017 using a quasi-random sampling (ie, patients were invited regardless of wether they were or had been previously exposed to MMH). Inclusion criteria were the age between 20 and 70 years and the willingness to participate in the study; exclusion criteria were history of metastatic cancer, spinal fractures, severe deformities of the spine (eg, scoliosis over $40^{\circ}$ ). Consent of each subject studied was obtained in writing, form approved by the ethics committee.

Prior or after the MRI examination, the patients were interviewed by an occupational physician. Personal and family history of musculoskeletal diseases and injuries, work history, current and previous exposure to biomechanical risk factors at work and during leisure time were assessed by means of a questionnaire; being involved in competitive sports (ie, follow a daily training and compete with each other) as well as information about the presence and frequency of manual material lifting, carrying, pushing or pulling, and awkward spine postures in the current and in previous jobs were collected.

To assess the exposure to $\mathrm{MMH}$ we adapted part of a questionnaire previously validated. ${ }^{15}$ Specifically, we evaluated the frequency of each task/posture as: never, sometimes, often, always/almost always. Moreover, lifting/ carrying activities were classified according to the weight of the load: $<5 \mathrm{~kg}$, from 5 to $15 \mathrm{~kg}$, from 15 to $25 \mathrm{~kg}$ and
$>25 \mathrm{~kg}$. For each class of weight, the subject had to indicate the frequency of lifting/carrying as: never, sometimes, often, always/almost always. The occupational physician was blinded to the results of the MRI at the time of the interview and the radiologist was blinded to the results of the interview when examining the MRI images.

Before pairing the interviews with the results of the MRI, MMH was coded for each subject according to the job title. White collar workers (administrative, teachers, managers, call centre operators) formed the control (unexposed) group, while subjects working or having worked in an occupation in which MMH is currently considered to be a typical occupational risk were considered exposed and were divided into three categories based on increasing physical work load. The job exposure matrix (JEM) proposed by Seidler et al was used as reference. ${ }^{16}$ Technicians, police officers, soldiers, hairdressers, biologists, physicians, nursery home teachers and retailers were classified as exposed to low physical MMH workload. Maintenance workers, waiters, grocery stores workers, electrical and electronics workers, painters, barmen, caregivers/in-home nurses were included in the middle group. Finally, in the high physical workload group, we comprised agricultural and construction workers, nurses, warehouse and production workers.

Current and previous jobs lasting for $>5$ years and occurring in the last 10 years were considered for classification. In case of divergence, the job with the highest intensity of MMH was used to define the physical load. Patients' own assessment of MMH was also applied to classify participants as unexposed (never lifting/carrying activities or sometimes lifting weight $<5 \mathrm{~kg}$ ) or exposed into three groups according to the frequency of lifting/ carrying activities (sometimes; often; always) or of the weight handled (sometimes from 5 to $15 \mathrm{~kg}$; sometimes $>15 \mathrm{~kg}$ or often up to $15 \mathrm{~kg}$; often $>15 \mathrm{~kg}$ or always any weight). Then, the three classes (low MMH workload, intermediate MMH workload, high MMH workload) of MMH based on job title were compared with the detailed description of MMH given by the patients, and they were found to be corresponding.

Each MRI examination was coded, for each vertebral body and intervertebral disc, as described below.

Lumbar intervertebral disc degeneration was graded according to the Pfirrmann et $a l^{17}$ classification system based on the following parameters: structure of the disc, distinction of nucleus and annulus, MRI signal intensity, height of intervertebral disc. For the purpose of the analysis, we considered three categories: 0 included Pfirmann's I and II (homogeneous or inhomogeneous structure with or without horizontal bands, clear distinction of nucleus and annulus, hyperintense or isointense signal to cerebrospinal fluid, normal disc height); 1 included Pfirmann's III (inhomogeneous grey structure, unclear distinction of nucleus and annulus, intermediate signal intensity, normal to slightly decreased disc height) and finally category 3 included Pfirmann's IV and V (inhomogeneous grey to black structure, lost distinction of nucleus and annulus, 
intermediate to hypointense signal, normal to moderately decreased disc height or collapsed disc space).

Disc morphology was classified as normal, bulging, protrusion and extrusion, according to the shape of the observed 'disc extension beyond the interspace', aka DEBIT. ${ }^{18}$ DEBIT 0 corresponded to a 'normal' condition (no disc material extending beyond the periphery of the disc space), DEBIT 1 meant 'bulging' (ie, circumferential symmetric disc tissue extending beyond the endplate $>50 \%$ ), DEBIT 2 to 4 corresponded to 'protrusion' and DEBIT 5 to 8 were related to 'extrusion'.

Signal changes in the vertebral bone marrow adjacent to the end plates was categorised according to the modification of signal intensity on $\mathrm{T} 1$ and $\mathrm{T} 2$ weighted spin echo of MRI examination, aka Modic changes. ${ }^{19}$ Modic category 0 meant a normal condition, Modic 1 bone marrow oedema, Modic 2 fatty degeneration and Modic 3 bone sclerosis.

The presence and distribution of osteophytes in lumbar vertebrae was classified into three categories: absent, discontinuous and continuous. ${ }^{20}$

The degree of spondylolystesis ${ }^{21}$ was measured and graded into six categories: absent, $<25 \%, 25 \%-50 \%$, $50 \%-75 \%, 75 \%-100 \%,>100 \%$.

\section{Patient and public involvement}

Patients or the public were not involved in this study.

\section{Statistical analysis}

Statistical analysis was carried out using Stata V.15.1 SE. Summary statistics were expressed as percentages or mean and SD as appropriate.

In our study, we considered Modic changes above grade 0 , DEBIT changes above grade 1 in one or two discs (at any level of the lumbar spine), DEBIT changes above grade 1 at L4-L5 and L5-S1 level. Pfirmann changes above grade 2 and presence of osteophytes in lumbar vertebrae were assessed at any level and at L4-L5 and L5-S1.

Independent two-sample Student's t-test was used to compare current LBP intensity score on a 0-10 visual analogue scale between not exposed and exposed to MMH.

The correlation between occupational exposure to $\mathrm{MMH}$ and each lumbar spine outcome was assessed with the Spearman's rank correlation coefficient

Associations of lumbar spine outcomes with risk factors were characterised by prevalence ratios (PRs) and associated 95\% CIs, estimated by fitting Poisson regression models with robust SEs clustered on the three centres.

For analysis of the risk of developing one of the lumbar spine outcomes, we examined the individual-level risk factors: sex, age, competitive sport, body mass index (BMI), smoke history, length of the occupational exposure to $\mathrm{MMH}$, familiar history of lumbar disc disease. Age was classified in two categories ( 45 years or less and more than 45 years).

Variables that reached a $p$ value $<0.1$ at univariate analysis for at least one of the lumbar spine outcomes were introduced in multivariate models: after preliminary analysis, gender, age, BMI, familiar history of lumbar disc disease and competitive sport were retained as covariates in multivariate models. Age group and exposure to $\mathrm{MMH}$ were entered as categorical variables, competitive sport as a dichotomous variable and BMI as a continuous variable.

Population attributable fractions (PAFs), defined as the percentage of cases attributable to the characteristic of interest were estimated after fitting regression models by means of maximum likelihood methods. ${ }^{22} \mathrm{P}$ values $<0.05$ were considered significant.

\section{RESULTS}

A total of 189 subjects performed an MRI at lumbar level and were invited to participate. Only two patients refused to fill in the questionnaire. Finally, the Bologna centre contributed 83 subjects to the study, Bari 75 and Brescia 29. Three subjects with a history of spinal fractures and one affected by scoliosis over $40^{\circ}$ were excluded prior to the analysis, leaving 183 subjects.

The demographic characteristics of the patients studied are reported in table 1: no statistically significant difference was found for personal characteristics between patients who were classified as exposed to MMH (any duration) and their not-exposed counterpart, for both sexes. All subjects were symptomatic for LBP during the last 12 months, $84,8 \%$ reported pain in the last 7 days and $66.8 \%$ were disabled by LBP. Exposed and unexposed subjects showed no differences in the characteristics of current LBP: the mean score on a $0-10$ visual analogue scale was 5.9 (SD 2.2) and 5.3 (SD 2.5), respectively $(\mathrm{p}=0.14)$.

Among exposed males (62 subjects) the intermediate class of exposure to MMH was underrepresented (9 subjects), whereas the same was true for the first class of exposure (9 subjects) among exposed females.

Crude prevalence of vertebral and disc changes in exposed and unexposed subjects are reported by gender in table 2: among exposed males (62 subjects) DEBIT changes in two discs (regardless of the level) and in L4-L5 were more prevalent, as were Modic changes and osteophytes (any level). Among exposed females (46 subjects) only DEBIT changes in one disc (regardless of the level) were slightly more prevalent.

The PRs of lumbar spine outcomes and personal and occupational characteristics are reported in table $3 \mathrm{~A}$ for disc morphology and disc degeneration and in table 3B for lumbar vertebral findings. In the multivariate model, age over 45 years was significantly associated with all the spine outcomes, whereas class of exposure to MMH was not. Male sex was significantly associated with DEBIT changes in one disc any level as well as L4-L5 and L5-S1, whereas there was suggestive evidence for the same association for Modic changes.

No significant correlation resulted between increasing exposure to MMH and any vertebral or disc outcome in both age groups ( $\leq 45$ or $>45$ years old). 
Table 1 Characteristics of the patient studied

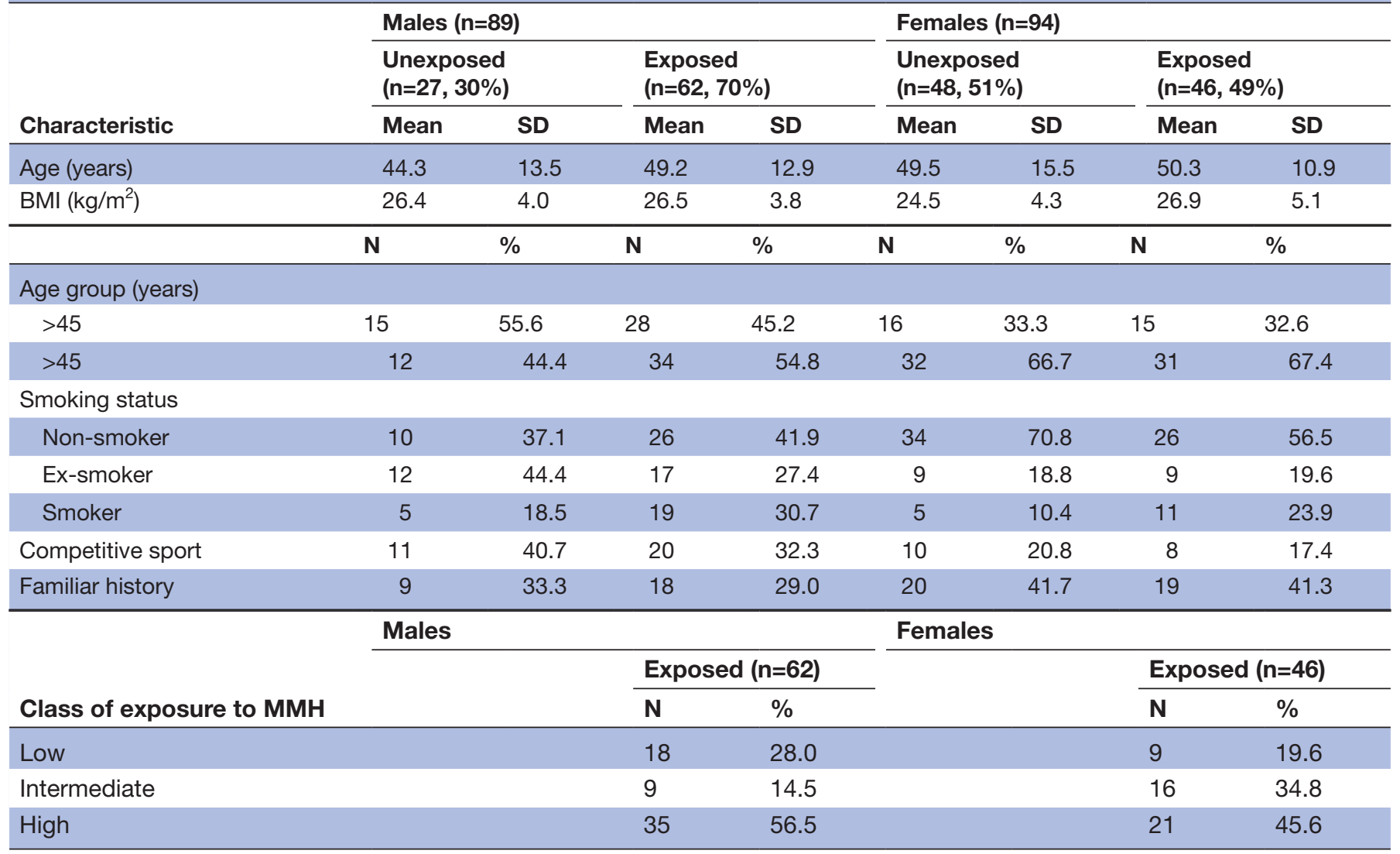

$\mathrm{BMI}$, body mass index; $\mathrm{MMH}$, manual material handling.

Based on the reported multivariate risk estimates (tables 3A,B), we calculated the fractions of cases attributable in our study population to each risk factor (table 4). For DEBIT changes in more than two levels, Modic changes (any level) and osteophytes, about one-third of the cases could be attributed to age above 45 years. The contribution of age seems to be prevalent in L4 L5. Male gender contributed to $10 \%$ or $17 \%$ of Modic changes and DEBIT L5-S1,

Table 2 Prevalence of vertebral and disc changes

\begin{tabular}{|c|c|c|c|c|c|c|c|c|}
\hline \multirow[b]{3}{*}{ Characteristic of lumbar spine } & \multicolumn{4}{|c|}{ Male $(n=89)$} & \multicolumn{4}{|c|}{ Female $(n=94)$} \\
\hline & \multicolumn{2}{|c|}{ Unexposed $(n=27)$} & \multicolumn{2}{|c|}{ Exposed $(n=62)$} & \multicolumn{2}{|c|}{ Unexposed $(n=48)$} & \multicolumn{2}{|c|}{ Exposed $(n=46)$} \\
\hline & $\mathbf{N}$ & $\%$ & $\mathbf{N}$ & $\%$ & $\mathbf{N}$ & $\%$ & $\mathbf{N}$ & $\%$ \\
\hline DEBIT>1 (2, any level) & 8 & 29.6 & 32 & 51.6 & 27 & 56.3 & 19 & 41.3 \\
\hline DEBIT>1 (L4-L5 level) & 8 & 29.6 & 33 & 53.2 & 21 & 43.8 & 21 & 45.7 \\
\hline Pfirrmann changes L4-L5 & 13 & 48.2 & 30 & 48.4 & 25 & 52.1 & 26 & 56.5 \\
\hline Pfirrmann changes L5-S1 & 16 & 59.3 & 34 & 54.8 & 33 & 68.8 & 22 & 47.8 \\
\hline Modic changes (any level) & 11 & 40.7 & 32 & 51.6 & 22 & 45.8 & 21 & 45.7 \\
\hline Modic changes L4 & 6 & 22.2 & 16 & 25.8 & 11 & 22.9 & 14 & 30.4 \\
\hline Modic changes L5 & 7 & 25.9 & 26 & 41.9 & 19 & 39.6 & 14 & 30.4 \\
\hline Osteophytes L5-S1 & 10 & 37.0 & 32 & 51.6 & 28 & 58.3 & 21 & 45.7 \\
\hline
\end{tabular}

DEBIT, disc extension beyond the interspace. 
Table 3A Associations between lumbar spine outcomes and personal characteristics: disc morphology and disc degeneration. Prevalence ratios and $95 \% \mathrm{Cls}$

\begin{tabular}{|c|c|c|c|c|c|}
\hline \multirow[b]{2}{*}{ Characteristic } & \multirow[b]{2}{*}{$\mathbf{N}$} & \multicolumn{2}{|c|}{ Univariate analysis } & \multicolumn{2}{|c|}{ Multivariate model ${ }^{*}$} \\
\hline & & PR & $95 \% \mathrm{Cl}$ & PR & $95 \% \mathrm{Cl}$ \\
\hline \multicolumn{6}{|c|}{ DEBIT (1, any level) } \\
\hline \multicolumn{6}{|l|}{ Sex } \\
\hline Female & 94 & 1.00 & Ref. & 1.00 & Ref. \\
\hline Male & 89 & 1.01 & 0.53 to 1.01 & 1.11 & 1.00 to 1.23 \\
\hline \multicolumn{6}{|l|}{ Age (years) } \\
\hline$\leq 45$ & 74 & 1.00 & Ref. & 1.00 & Ref. \\
\hline$>45$ & 109 & 1.15 & 1.04 to 1.29 & 1.15 & 1.05 to 1.26 \\
\hline \multicolumn{6}{|c|}{ Class of exposure to $\mathrm{MMH}$} \\
\hline No exposure & & 1.00 & Ref. & 1.00 & Ref. \\
\hline Low & 27 & 1.03 & 0.74 to 1.42 & 1.03 & 0.82 to 1.31 \\
\hline Intermediate & 25 & 1.06 & 0.88 to 1.27 & 1.11 & 0.89 to 1.39 \\
\hline High & 56 & 1.04 & 0.92 to 1.17 & 0.99 & 0.91 to 1.07 \\
\hline \multicolumn{6}{|c|}{ DEBIT $(2$, any level) } \\
\hline \multicolumn{6}{|l|}{ Sex } \\
\hline Female & 94 & 1.00 & Ref. & 1.00 & Ref. \\
\hline Male & 89 & 0.92 & 0.58 to 1.45 & 1.10 & 0.77 to 1.57 \\
\hline \multicolumn{6}{|l|}{ Age (years) } \\
\hline$\leq 45$ & 74 & 1.00 & Ref. & 1.00 & Ref. \\
\hline$>45$ & 109 & 1.86 & 1.11 to 3.11 & 1.85 & 1.16 to 2.95 \\
\hline \multicolumn{6}{|c|}{ Class of exposure to $\mathrm{MMH}$} \\
\hline No exposure & & 1.00 & Ref. & 1.00 & Ref. \\
\hline Low & 27 & 1.03 & 0.82 to 1.30 & 1.10 & 1.03 to 1.17 \\
\hline Intermediate & 25 & 0.94 & 0.38 to 2.33 & 1.04 & 0.48 to 2.28 \\
\hline High & 56 & 1.03 & 0.70 to 1.53 & 0.96 & 0.70 to 1.32 \\
\hline \multicolumn{6}{|c|}{ DEBIT (1, L4-L5 level) } \\
\hline \multicolumn{6}{|l|}{ Sex } \\
\hline Female & 94 & 1.00 & Ref. & 1.00 & Ref. \\
\hline Male & 89 & 1.03 & 0.81 to 1.31 & 1.17 & 1.09 to 1.25 \\
\hline \multicolumn{6}{|l|}{ Age (years) } \\
\hline$\leq 45$ & 74 & 1.00 & Ref. & 1.00 & Ref. \\
\hline$>45$ & 109 & 1.41 & 1.13 to 1.76 & 1.39 & 1.09 to 1.78 \\
\hline \multicolumn{6}{|c|}{ Class of exposure to $\mathrm{MMH}$} \\
\hline No exposure & & 1.00 & Ref. & 1.00 & Ref. \\
\hline Low & 27 & 1.15 & 0.85 to 1.55 & 1.18 & 1.03 to 1.36 \\
\hline Intermediate & 25 & 1.24 & 0.81 to 1.89 & 1.37 & 0.96 to 1.94 \\
\hline High & 56 & 1.39 & 0.97 to 1.97 & 1.27 & 0.94 to 1.72 \\
\hline \multicolumn{6}{|c|}{ DEBIT (1, L5-S1 level) } \\
\hline \multicolumn{6}{|l|}{ Sex } \\
\hline Female & 94 & 1.00 & Ref. & 1.00 & Ref. \\
\hline Male & 89 & 1.32 & 0.92 to 1.89 & 1.45 & 1.03 to 2.04 \\
\hline \multicolumn{6}{|l|}{ Age (years) } \\
\hline$\leq 45$ & 74 & 1.00 & Ref. & 1.00 & Ref. \\
\hline$>45$ & 109 & 1.00 & 0.90 to 1.11 & 1.01 & 0.95 to 1.08 \\
\hline \multicolumn{6}{|c|}{ Class of exposure to $\mathrm{MMH}$} \\
\hline No exposure & & 1.00 & Ref. & 1.00 & Ref. \\
\hline Low & 27 & 0.88 & 0.56 to 1.39 & 0.81 & 0.54 to 1.20 \\
\hline
\end{tabular}


Table 3A Continued

\begin{tabular}{|c|c|c|c|c|c|}
\hline \multirow[b]{2}{*}{ Characteristic } & \multirow[b]{2}{*}{$\mathbf{N}$} & \multicolumn{2}{|c|}{ Univariate analysis } & \multicolumn{2}{|c|}{ Multivariate model* } \\
\hline & & PR & $95 \% \mathrm{Cl}$ & PR & $95 \% \mathrm{Cl}$ \\
\hline Intermediate & 25 & 1.02 & 0.93 to 1.13 & 1.02 & 0.99 to 1.05 \\
\hline \multicolumn{6}{|c|}{ Pfirrmann changes } \\
\hline \multicolumn{6}{|l|}{ Sex } \\
\hline \multicolumn{6}{|l|}{ Age (years) } \\
\hline$\leq 45$ & 74 & 1.00 & Ref. & 1.00 & Ref. \\
\hline$>45$ & 109 & 1.36 & 1.10 to 1.68 & 1.33 & 1.10 to 1.61 \\
\hline \multicolumn{6}{|c|}{ Class of exposure to $\mathrm{MMH}$} \\
\hline High & 56 & 0.91 & 0.54 to 1.52 & 0.85 & 0.50 to 1.44 \\
\hline \multicolumn{6}{|c|}{ Pfirrmann changes L4-L5 } \\
\hline \multicolumn{6}{|l|}{ Sex } \\
\hline Female & 94 & 1.00 & Ref. & 1.00 & Ref. \\
\hline Male & 89 & 0.89 & 0.83 to 0.95 & 1.05 & 0.87 to 1.28 \\
\hline \multicolumn{6}{|l|}{ Age (years) } \\
\hline$\leq 45$ & 74 & 1.00 & Ref. & 1.00 & Ref. \\
\hline$>45$ & 109 & 1.68 & 1.19 to 2.39 & 1.59 & 1.15 to 2.21 \\
\hline \multicolumn{6}{|c|}{ Class of exposure to $\mathrm{MMH}$} \\
\hline Female & 94 & 1.00 & Ref. & 1.00 & Ref. \\
\hline Male & 89 & 0.96 & 0.75 to 1.22 & 1.13 & 0.82 to 1.58 \\
\hline \multicolumn{6}{|l|}{ Age (years) } \\
\hline$\leq 45$ & 74 & 1.00 & Ref. & 1.00 & Ref. \\
\hline$>45$ & 109 & 1.36 & 1.01 to 1.83 & 1.32 & 1.01 to 1.72 \\
\hline \multicolumn{6}{|c|}{ Class of exposure to $\mathrm{MMH}$} \\
\hline No exposure & & 1.00 & Ref. & 1.00 & Ref. \\
\hline Low & 27 & 0.62 & 0.31 to 1.25 & 0.63 & 0.30 to 1.32 \\
\hline Intermediate & 25 & 0.86 & 0.57 to 1.30 & 0.86 & 0.47 to 1.58 \\
\hline High & 56 & 0.85 & 0.50 to 1.45 & 0.78 & 0.46 to 1.31 \\
\hline
\end{tabular}

*Multivariate model included sex, age, body mass index, competitive sport, family history of lumbar disc disease and class of exposure to MMH DEBIT, disc extension beyond the interspace; $\mathrm{MMH}$, manual material handling; PR, prevalence ratio; Ref, reference category.

respectively. The PAF of lumbar spine outcomes for exposure to MMH was definitely low, only for DEBIT 1 L4-L5 reached $14 \%$.

\section{DISCUSSION}

The main result of this study is a lack of difference in the prevalence of lumbar vertebral body and disc changes between subjects exposed to significant MMH and those unexposed. As in any single observational study, this result may be a real effect or the product of chance, misclassification of exposure or misclassification of the outcome. Misclassification of exposure to MMH is possible, as exposure has been attributed based on self-reported occupational information. On site assessment data, based on 
Table 3B Associations between lumbar spine outcomes and personal characteristics: lumbar vertebral findings. Prevalence ratios and $95 \% \mathrm{Cls}$

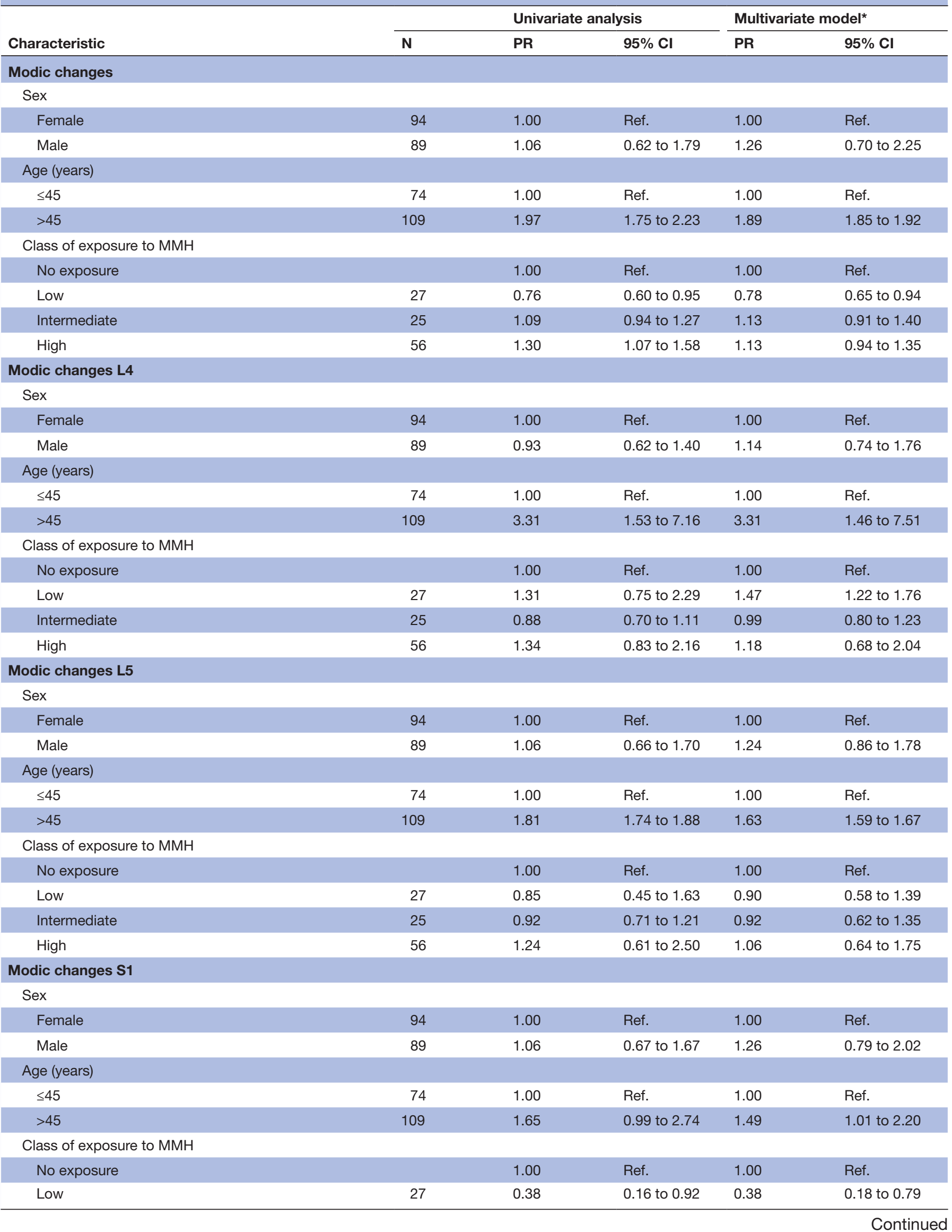


Table 3B Continued

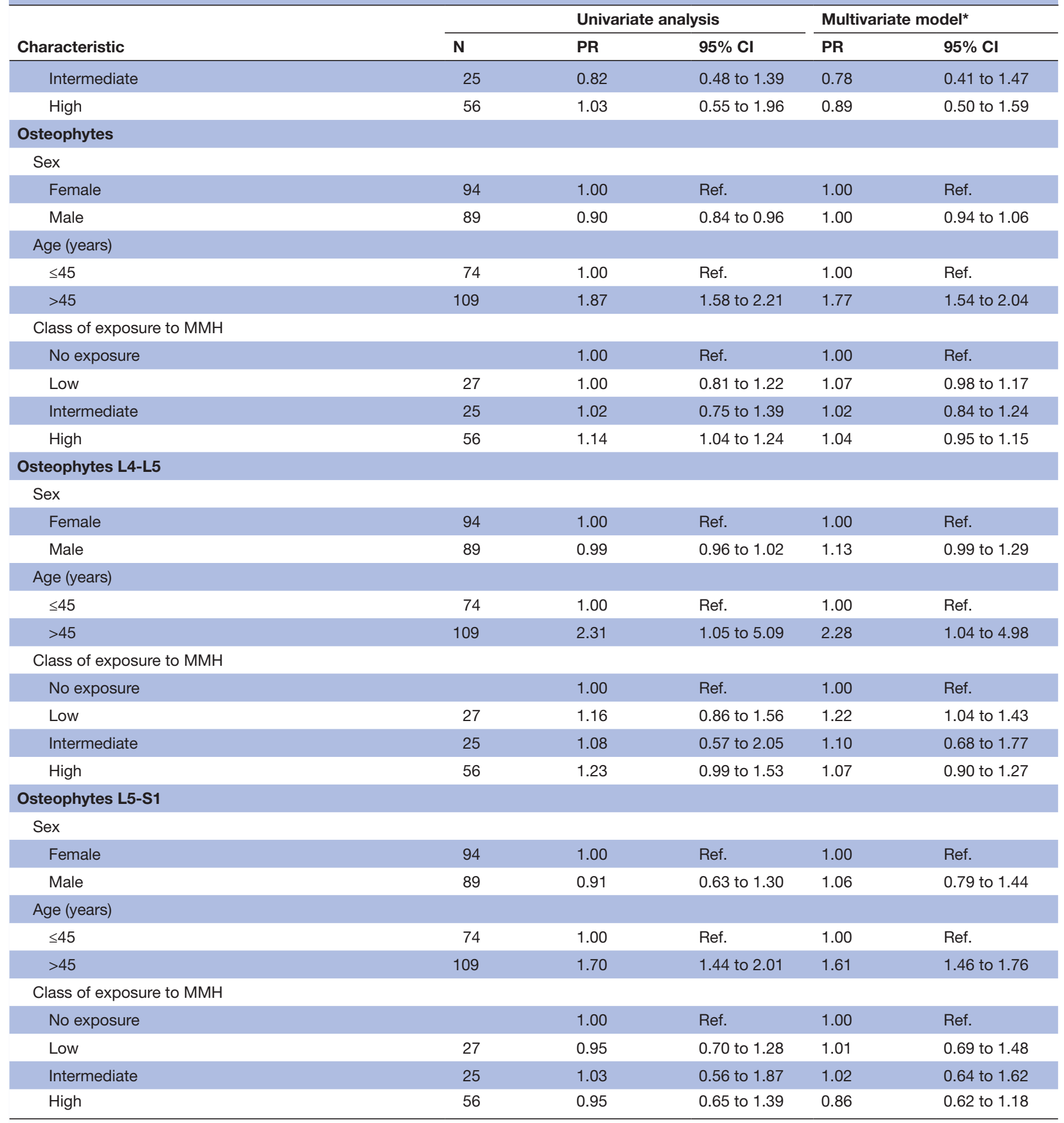

*Multivariate model included sex, age, body mass index, competitive sport, family history of lumbar disc disease and class of exposure to MMH PR, prevalence ratio; DEBIT, disc extension beyond the interspace; MMH, manual material handling; Ref., reference category.

observations or measures collected in the companies, are nearly all the time unavailable in epidemiological research. Thus, self-reported exposure collected by questionnaire is usually employed ${ }^{510-12}$ and are considered a source for recall bias and possibly overestimation of exposure. ${ }^{23}$ To manage this critical issue, exposure classification was attributed according to job title using the JEM proposed by Seidler $e t a l^{16}$ which provides an estimation of the lumbar spine force through lifting, carrying or extreme forward bending. Furthermore, the classification of MMH based on exposure data reported in the questionnaire proved to be consistent with the one based on the JEM. In addition, exposure classification was primarily attributed without any knowledge of 


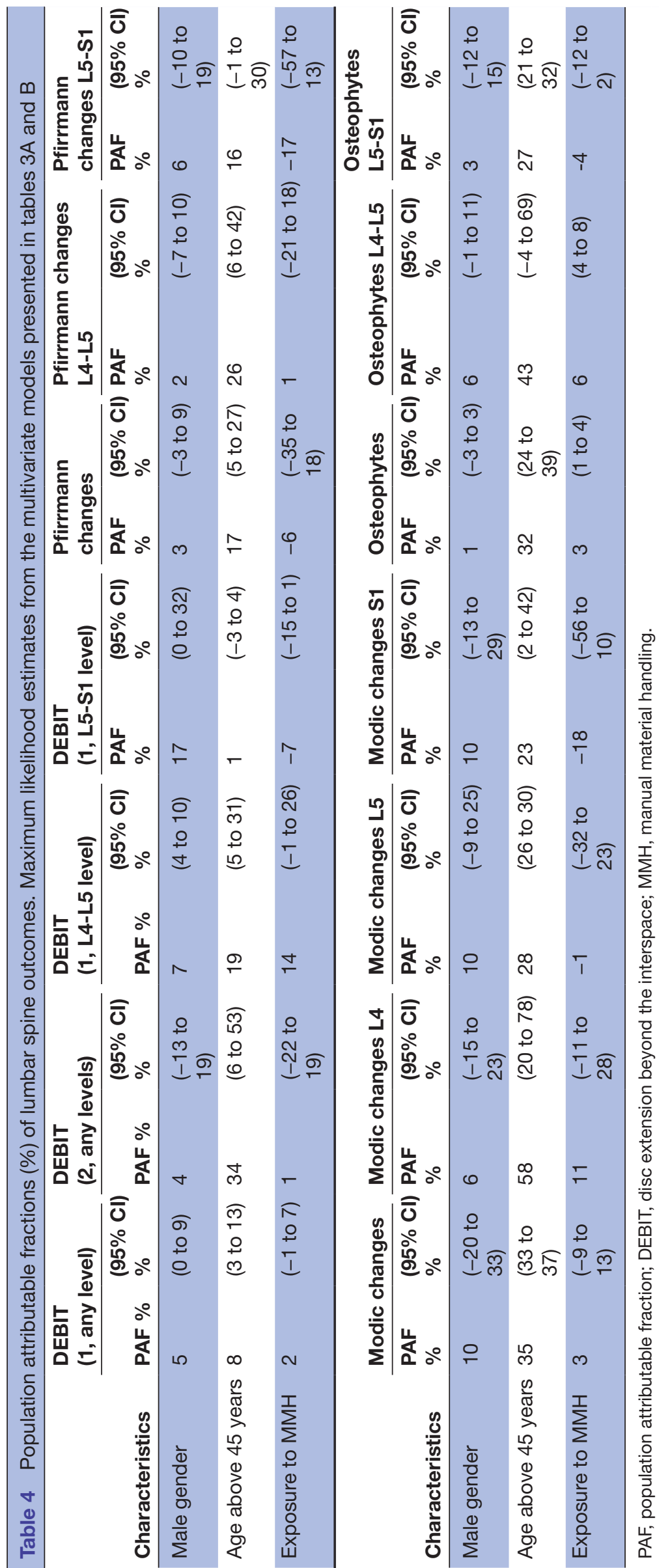


the MRI results so, if misclassification has occurred, it is likely to be non-differential. The same can be said about MRI results.

A lack of dominant or prevailing effect of occupational MMH on the MRI ascertainable changes of the lumbar spine is, to our opinion, the more plausible explanation of the results of this study: several lines of evidence point in this direction. Studies in human volunteers, back in the sixties, measured the increase of pressure to which lumbar spine is subjected during $\mathrm{MMH} .{ }^{24}$ So far, no convincing human evidence exists that a single, excessive compression of the lumbar spine can lead to intervertebral disc herniation: on the contrary, experimental studies have shown that 'when a compressive load is applied to a lumbar motion segment - the name given to two adjacent vertebra and their intervening disc-failure occurs first in the endplate, then in the vertebral bodies, and only after that in the disc proper' and 'disc hernias have been produced when the posterior part of the intervertebral motion segment is first removed and then the disc is loaded in compression and flexion. ${ }^{14}$ This experimental human evidence agrees with the common observation of vertebral body fractures during lifting in osteoporotic patients. ${ }^{25}$

Epidemiology of occupational MMH and lumbar disc disease is erratic; as a consequence, the exact contribution of biomechanical load in the multifactorial spectrum of etiological factors of lumbar vertebral body and disc changes is not completely understood.

Twin studies ${ }^{26}$ point to a much greater role of genetics than $\mathrm{MMH}$ in disc degeneration and the presence of disc disease even in young children (long before any MMH may have been performed) sustains the role of genetic predisposition. ${ }^{27}$ This is supported also by a case-control study showed that in younger subjects, genetics was the main risk factor for lumbar disc herniation, followed by spinal load and hard working; only among subjects older than 55 years spinal load was the main risk factor. ${ }^{10}$

On the other hand, a case-control study found a positive dose-response relationship between cumulative lumbar load and disc changes among men and women, but the results displayed different patterns according to gender: women showed an increased effect on disc herniation while for man the stronger effect was recorded for disc narrowing. ${ }^{4}$ In a Danish cohort, males were followed for 33 years $^{11}$ and investigated for hospitalisation due to herniated lumbar disc disease: a statistically significant association was found for strenuous manual work (resulting in sweating) but not for ergonomic load to the back. Exposed status was assigned at the inception of the cohort by questionnaire, and there was apparently no information whether exposure had changed during the follow-up. A register record linkage study investigated the same issue in 19 categories of workers engaged in the construction sector ${ }^{28}: 7$ of these categories did not show a statistically significant excess of hospitalisation due to lumbar disc disease in comparison to the control group of administrative workers; among the categories which showed a significant excess, however, the highest relative risk was for refrigerator technicians, who showed a risk greater than that of the bricklayers.

Other studies analysed MRI lumbar findings with respect to individual and occupational characteristics attaining heterogeneous results. A cohort study on subjects with LBP and lumbar disc disease ${ }^{29}$ showed that 'minor trauma', also associated with lifting, do not induce new clinically significant findings in MRI, furthermore a cross-sectional MRI study ${ }^{30}$ comparing female nurses with LBP (who performed manual patients and material handling) with administrative workers (unexposed), failed to show significant differences in lumbar disc changes between the two groups. Another cross-sectional MRI study ${ }^{31}$ showed that physical occupational exposure was not associated with the presence of lumbar disc degeneration and narrowing per se but with increased number of involved discs and tendency towards more severe disc height loss in subjects in whom disc degeneration was already present or in people with a possibly innate tendency to develop degeneration.

When analysing the distribution of MRI disc changes along the lumbar spine, in a Japanese elderly population age and BMI were associated with lumbar disc degeneration at any level, while occupational lifting was associated with disc disease only at L1-L2. ${ }^{12}$ Different conclusions are reported by Hung et al who suggest a dose-response relationship between cumulative lifting load and disk dehydration, disk height narrowing, and disk bulging, especially at the lower lumbar levels. More recently Jang $e t$ $a l^{33}$ showed that lumbar intervertebral disc degeneration (Pfirmann grade) increased with age and that field work such as firefighting, emergency and rescue may accelerate the effect of age on degeneration at the level L4-L5. Of note, the results of a 5-year longitudinal MRI study of 41 initially asymptomatic individuals challenge the hypothesis that the classic occupational physical risk factors have a strong and direct impact on disc degeneration. ${ }^{32}$

It is difficult to weight our figures against the results of the above mentioned studies given the different recruitment strategies, possible healthy workers effect among study groups recruited at company level, different age composition and individual characteristics conditioned by social, educational and dietary habits, especially if dealing with cultures from different Countries.

As stated earlier, current biomechanical knowledge supports the idea that if disc disease is due to spinal load induced by MMH, the damage should follow the same pattern of the load: this means that when studying subjects who perform MMH versus control subjects, one should expect to find a higher overall frequency of disc disease not at 'any level' but mostly at L5-S1 level, because it incurs the greatest load during MMH.

Our study was unable to show such a pattern, both as a higher frequency of any disc change in the subjects exposed to MMH and, specifically, as a concentration of abnormalities at L5-S1 level. The only consistent association found was between age above 45 years and disc 
changes; suggestive evidence was found for a higher frequency of Modic changes with age, too.

\section{Strengths and limitations of this study}

This multicentre study involves a sample of $>180$ subjects. It provides detailed information about lumbar intervertebral disc structure and morphology, as well as vertebral endplate and bone marrow changes, associated with personal and occupational factors. From a prevention perspective, our findings could contribute to the understanding of the role of lumbar mechanical load in the multifactorial aetiology of disc and vertebral degeneration.

Limitations of this study are the cross-sectional design and the self-reported questionnaire-based exposure assessment. Given the recruitment strategy no physical examination procedure was feasible. Another limitation is the lack of comparison among radiologists who independently read MRI within each participating centre; however, in order to enhance accuracy and repeatability, a preliminary consensus criterion was reached to describe lumbar vertebral and disc features.

Since the design of the study is not prospective, the study may not infer causality. Furthermore, a chance effect is always possible, and this can be ruled out, in the future, only by independent replication of this study, which may show if the results here reported are stable.

In view of the less than optimal information presently available about MMH as a possible cause of lumbar vertebral body and disc changes, further high-quality studies are necessary (prospective design, careful individual investigation of $\mathrm{MMH}$ according the best available techniques, accurate standardised coding of lumbar spine changes at any of the levels, exposure and outcome assessors blind to each other).

\section{CONCLUSIONS}

In summary, this report found that age, and not MMH, seems to primarily affect the presence of lumbar intervertebral disc changes; in order to target preventive strategies towards populations at risk, there is a need of prospective studies to better explore the relationship between MMH and the possible presence (and level) of lumbar vertebral body and/or disc changes.

Acknowledgements We would like to thank the Lumbar Disc Disease Study Group: Lead Author: Leonardo Soleo MD, Interdisciplinary Department of Medicine, Università di Bari, Bari, Italy. Andrea Andreone MD, Dimitris Papadopoulos MD, Lea Bono MD, Department of Experimental, Diagnostic and Specialty Medicine, Alma Mater Studiorum Università di Bologna. Angela Camagni MD, Matteo Di Lello MD, Department of Medical and Surgical Sciences, Alma Mater Studiorum Università di Bologna. Franca Di Cuonzo MD, Ignazio Salvemini MD, Department of Basic Medical Sciences, Neuroscience and Sense Organs, Università di Bari, Bari, Italy. Rossana Rotondi MD, Interdisciplinary Department of Medicine, Università di Bari, Bari, Italy. Roberto Gasparotti MD, Department of Medical and Surgical Sciences, Radiological Sciences and Public Health, Università di Brescia. Jacopo Fostinelli MD, Department of Medical and Surgical Sciences, Radiological Sciences and Public Health, Università di Brescia.

Contributors FSV: conception and design of the work; interpretation of data for the work; drafting the work; final approval of the version to be published; agreement to be accountable for all aspects of the work. MZ and PA: contributions to the acquisition of data for the work; revising the work critically for important intellectual content; final approval of the version to be published; agreement to be accountable for all aspects of the work. PL: contributions to the acquisition of data for the work; revising the work critically for important intellectual content after first submission. FM: contributions to the acquisition of data for the work; data analysis; revising the work critically for important intellectual content; final approval of the version to be published; agreement to be accountable for all aspects of the work. RB: substantial contributions to the conception and design of the work; interpretation of data for the work; drafting the work; final approval of the version to be published; agreement to be accountable for all aspects of the work.

Funding The authors have not declared a specific grant for this research from any funding agency in the public, commercial or not-for-profit sectors.

Competing interests None declared.

Patient consent for publication Not required.

Ethics approval Ethics committee of S.Orsola-Malpighi Hospital approved the study (070/2013/U/0ss).

Provenance and peer review Not commissioned; externally peer reviewed.

Data availability statement Data are available in a public, open access repository.

Open access This is an open access article distributed in accordance with the Creative Commons Attribution Non Commercial (CC BY-NC 4.0) license, which permits others to distribute, remix, adapt, build upon this work non-commercially, and license their derivative works on different terms, provided the original work is properly cited, appropriate credit is given, any changes made indicated, and the use is non-commercial. See: http://creativecommons.org/licenses/by-nc/4.0/.

\section{REFERENCES}

1. Hartvigsen J, Hancock MJ, Kongsted A, et al. What low back pain is and why we need to pay attention. Lancet 2018;391:2356-67.

2. Hoogendoorn WE, van Poppel MN, Bongers PM, et al. Physical load during work and leisure time as risk factors for back pain. Scand $J$ Work Environ Health 1999;25:387-403.

3. Roffey DM, Wai EK, Bishop P, et al. Causal assessment of workplace manual handling or assisting patients and low back pain: results of a systematic review. Spine J 2010;10:639-51.

4. Seidler A, Bergmann A, Jäger M, et al. Cumulative occupational lumbar load and lumbar disc disease - results of a German multicenter case-control study (EPILIFT). BMC Musculoskelet Disord 2009;10:48.

5. Hung Y-J, Shih TT-F, Chen B-B, et al. The dose-response relationship between cumulative lifting load and lumbar disk degeneration based on magnetic resonance imaging findings. Phys Ther 2014;94:1582-93.

6. Violante FS, Mattioli S, Bonfiglioli R, et al. Low-back pain. Handb Clin Neurol 2015;131:397-410.

7. Battié MC, Videman T, Gibbons LE, et al. 1995 Volvo award in clinical sciences. Determinants of lumbar disc degeneration. A study relating lifetime exposures and magnetic resonance imaging findings in identical twins. Spine 1995;20:2601-12.

8. Sambrook PN, MacGregor AJ, Spector TD. Genetic influences on cervical and lumbar disc degeneration: a magnetic resonance imaging study in twins. Arthritis Rheum 1999;42:366-72.

9. Battié MC, Videman T, Levälahti E, et al. Genetic and environmental effects on disc degeneration by phenotype and spinal level: a multivariate twin study. Spine 2008;33:2801-8.

10. Zhang Y-gang, Sun Z, Zhang Z, et al. Risk factors for lumbar intervertebral disc herniation in Chinese population: a case-control study. Spine 2009;34:E918-E922.

11. Sørensen IG, Jacobsen P, Gyntelberg F, et al. Occupational and other predictors of herniated lumbar disc disease-a 33-year follow-up in the Copenhagen male study. Spine 2011;36:1541-6.

12. Hangai M, Kaneoka K, Kuno S, et al. Factors associated with lumbar intervertebral disc degeneration in the elderly. Spine $J$ 2008;8:732-40.

13. Jang T-W, Ahn Y-S, Byun J, et al. Lumbar intervertebral disc degeneration and related factors in Korean firefighters. BMJ Open 2016;6:e011587.

14. Chaffin DB, Gunnar Andersson GBJ, Martin BJ. The Structure and Function of the Musculoskeletal System (Chapter 2) and Occupational Biomechanical Models (Chapter 6). In: Occupational biomechanics. 4th edn. John Wiley \& Sons, 2006. 
15. Sjøgaard G, Søgaard K, Hermens HJ, et al. Neuromuscular assessment in elderly workers with and without work related shoulder/neck trouble: the NEW-study design and physiological findings. Eur J Appl Physiol 2006:96:110-21.

16. Seidler A, Bolm-Audorff $U$, Heiskel $\mathrm{H}$, et al. The role of cumulative physical work load in lumbar spine disease: risk factors for lumbar osteochondrosis and spondylosis associated with chronic complaints. Occup Environ Med 2001;58:735-46.

17. Pfirrmann CW, Metzdorf A, Zanetti M, et al. Magnetic resonance classification of lumbar intervertebral disc degeneration. Spine 2001;26:1873-8.

18. Brant-Zawadzki MN, Jensen MC, Obuchowski N, et al. Interobserver and intraobserver variability in interpretation of lumbar disc abnormalities. A comparison of two nomenclatures. Spine 1995;20:1257-64.

19. Modic MT, Steinberg PM, Ross JS, et al. Degenerative disk disease: assessment of changes in vertebral body marrow with MR imaging. Radiology 1988;166:193-9.

20. Benneker LM, Heini PF, Anderson SE, et al. Correlation of radiographic and MRI parameters to morphological and biochemical assessment of intervertebral disc degeneration. Eur Spine $J$ 2005;14:27-35.

21. Meyerding HW. Spondylolisthesis. Surg Gynecol Obstet 1932;54:371-7.

22. Newson RB. Attributable and unattributable risks and fractions and other scenario comparisons. Stata J 2013;13:672-98.
23. Kuijer PPFM, Verbeek JH, Seidler A, et al. Work-relatedness of lumbosacral radiculopathy syndrome: review and dose-response meta-analysis. Neurology 2018;91:558-64.

24. Nachemson A, Morris J. Lumbar discometry. lumbar intradiscal pressure measurements in vivo. Lancet 1963;1:1140-2.

25. McCarthy J, Davis A. Diagnosis and management of vertebral compression fractures. Am Fam Physician 2016;94:44-50.

26. Battié MC, Videman T, Kaprio J, et al. The twin spine study: contributions to a changing view of disc degeneration. Spine $J$ 2009;9:47-59.

27. Haidar R, Ghanem I, Saad S, et al. Lumbar disc herniation in young children. Acta Paediatr 2010;99:19-23.

28. Wahlström J, Burström L, Nilsson T, et al. Risk factors for hospitalization due to lumbar disc disease. Spine 2012;37:1334-9.

29. Carragee E, Alamin T, Cheng I, et al. Does minor trauma cause serious low back illness? Spine 2006;31:2942-9.

30. Schenk P, Läubli T, Hodler J, et al. Magnetic resonance imaging of the lumbar spine: findings in female subjects from administrative and nursing professions. Spine 2006;31:2701-6.

31. Mariconda M, Galasso O, Imbimbo L, et al. Relationship between alterations of the lumbar spine, visualized with magnetic resonance imaging, and occupational variables. Eur Spine J 2007;16:255-66.

32. Elfering $A$, Semmer N, Birkhofer $D$, et al. Risk factors for lumbar disc degeneration: a 5-year prospective MRI study in asymptomatic individuals. Spine 2002;27:125-34. 